\title{
THE LATEX SLIDE TEST IN RHEUMATIC DISORDERS
}

BY

\author{
J. V. WILSON, R. A. H. MORISON, AND V. WRIGHT \\ From the Royal Bath Hospital, Harrogate
}

(RECEIVED FOR PUBLICATION JULY 11, 1960)

\begin{abstract}
The latex slide test (L.S.T.) has been shown to be simple to perform and easy to read. It gives results comparable with the more complicated serological procedures used in the diagnosis of rheumatoid arthritis.

In 603 cases the L.S.T. and differential agglutination test gave a high degree of correlation. There were only four discrepancies between the two tests. The L.S.T. is the more practicable for routine laboratory use.

The L.S.T. has been correlated with the duration, activity, and extent of rheumatoid arthritis, and also with the erythrocyte sedimentation rate, haemoglobin level, and radiographic appearances. The various serological tests are tabulated.
\end{abstract}

It has repeatedly been shown that the serum of a large percentage of patients with rheumatoid arthritis gives a characteristic agglutination reaction often to a high titre. Many techniques have been employed to demonstrate this reaction. We have evaluated clinically and serologically the latex slide test (L.S.T.) and compared it with the differential agglutination test (D.A.T.).

\section{Methods and Material}

The L.S.T. was carried out according to the method described by the makers (Hyland Laboratories). In principle this involves the use of polystyrene latex particles coated with a globulin-containing reagent, and their subsequent flocculation by rheumatoid serum. The test was read macroscopically after one minute and the result designated positive, weak positive, or negative depending on the degree of flocculation.

The D.A.T. was carried out by a modification of the techniques of Rose, Ragan, Pearce, and Lipman (1948) and Heller, Jacobson, Kolodny, and Kammerer (1954), described by Greenbury (1957). A differential titre of 16 or above was considered positive. Haemoglobin was measured by the alkaline haematin method $(100 \%=14.8 \mathrm{~g}$. haemoglobin per $100 \mathrm{ml}$. blood), and the erythrocyte sedimentation rate by the Westergren method.

Six hundred and three patients examined at the Royal Bath Hospital between November, 1958, and March, 1960, were assessed, the diagnosis being made without reference to the serological results. Patients were also classified according to the criteria laid down by the American Rheumatism Association (Ropes, Bennett, Cobb, Jacox, and Jessar, 1959), using the categories definite, probable, and possible. The extent of the disease was graded as severe, moderate, or mild; the activity as severe, moderate, or inactive. Radiographs were taken where indicated.

\section{Serological Comparison}

Of the 603 patients, 232 had a positive L.S.T., 24 had a weakly positive L.S.T., and 347 gave a negative result. In only four instances was there a discrepancy between the two tests and in each of these cases the L.S.T. was positive while the D.A.T. was negative. A close correlation was found between the D.A.T. titre and the L.S.T. results. All sera giving a weak positive L.S.T. produced a D.A.T. of 64 or less, with one exception. This was from a man aged 58 years, with osteoarthritis for seven years, who had a D.A.T. of 1,024 and a weakly positive L.S.T.

The four patients whose tests were not in agreement are shown in Table I. The two with definite rheumatoid arthritis were women in the third decade with histories of four and six years respectively. The third patient was a woman aged 68 years with primary generalized osteoarthritis of 11 years' duration who had some features suggesting rheumatoid arthritis. The fourth patient was a 62-year-old man with a history of generalized osteoarthritis for 18 years.

\section{General Survey of Results}

The results of the L.S.T. in relation to the diagnoses are shown in Table I. The L.S.T. was positive in $85 \%$ of patients with definite or probable rheumatoid arthritis, but less than half the cases in the "possible" group were positive. 
TABLE I

RESULTS OF D.A.T. AND L.S.T. IN RHEUMATIC DISORDERS

\begin{tabular}{|c|c|c|c|c|}
\hline$\underset{\text { Diagnosis }}{\text { Clinical }}$ & Total & $\begin{array}{l}\text { D.A.T. } \\
\text { and } \\
\text { L.S.T. } \\
\text { Positive }\end{array}$ & $\begin{array}{l}\text { D.A.T. } \\
\text { Negative } \\
\text { L.S.T. } \\
\text { Positive }\end{array}$ & $\begin{array}{l}\text { Percen- } \\
\text { tage } \\
\text { L.S.T. } \\
\text { Positive }\end{array}$ \\
\hline 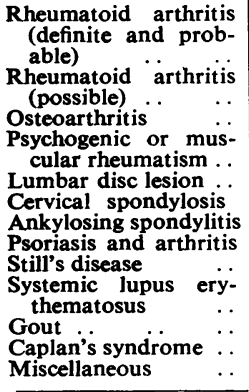 & $\begin{array}{r}246 \\
48 \\
131 \\
53 \\
25 \\
18 \\
12 \\
14 \\
11 \\
6 \\
6 \\
3 \\
30\end{array}$ & $\begin{array}{r}20 \\
5 \\
1 \\
0 \\
1 \\
1 \\
4 \\
1\end{array}$ & $\begin{array}{l}1 \\
= \\
= \\
= \\
= \\
= \\
=\end{array}$ & $\begin{array}{l}85 \\
44 \\
5 \cdot 3 \\
2 \\
= \\
= \\
= \\
= \\
=\end{array}$ \\
\hline & 603 & 252 & 4 & \\
\hline
\end{tabular}

It was found that only nine out of 233 patients in whom there was no suggestion of rheumatoid arthritis had a positive test $(3.8 \%$ " false positives"). The corresponding figure for 131 patients with osteoarthritis was $5.3 \%$, emphasizing the usefulness of the test in differentiating these cases from rheumatoid arthritis. The absence of a positive L.S.T. in all but one of the patients with muscular rheumatism indicates the value of the test in excluding rheumatoid disease.

Patients with psoriasis and atrophic arthritis have been tabulated separately since there are good reasons for considering that they contain a group with an arthritis distinct from rheumatoid arthritis (Wright, 1959). It was interesting to note that only one patient with ankylosing spondylitis and one case of Still's disease had positive tests.

The miscellaneous group comprised eight patients with periarthritis of the shoulder (one positive), four with tenosynovitis, two with rheumatic fever, three with Reiter's syndrome, two with palindromic rheumatism (one positive), and two with Raynaud's disease (one positive). There were single cases of subacute bacterial endocarditis, undulant fever, dermatomyositis, colitic arthritis, pyogenic arthritis, spinal tumour, monarticular arthritis, and traumatic arthritis which were all negative, and finally a case of intermittent hydrarthrosis which was positive.

\section{Findings in Rheumatoid Arthritis}

Using the diagnostic criteria laid down by the American Rheumatism Association, patients with rheumatoid arthritis were classified as definite, probable, and possible. Of 216 in the first group $90 \%$ had a positive test; the probable group comprised 58 patients of whom $55 \%$ were positive, whilst in the remaining group of 20 with possible rheumatoid arthritis only four $(20 \%)$ had a positive L.S.T. In all groups, the males showed a consistently higher percentage of positive results.

The results of the L.S.T. in relation to duration of disease in the definite and probable rheumatoid arthritics are shown in Fig. 1. The lower percentages of positive tests occurred in the early and long-standing groups. However, of 16 patients seen within six months of onset, 12 tests were positive, and a further one was weakly positive.

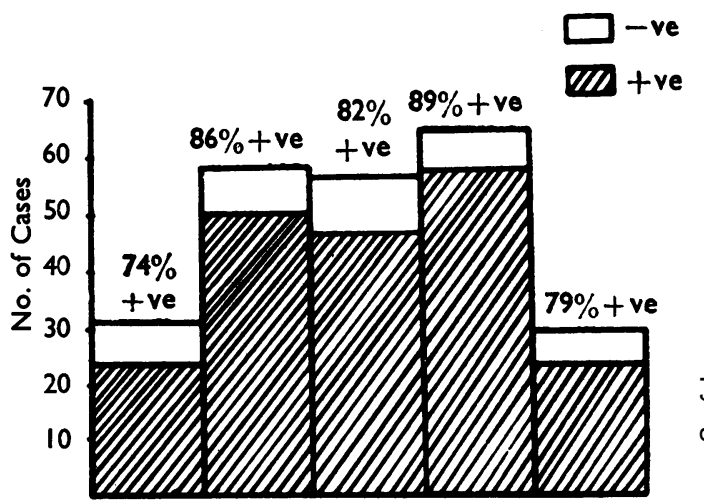

Under I yr. 1-5 yr. 5-10 yr. 10-20 yr. Over 20 yr. Duration of Rheumatoid Arthritis

FIG. 1.-Results of the L.S.T. related to the duration of rheumatoid arthritis.

Patients with arthritis which was mild in extent showed a smaller percentage of positive results $(74 \%)$ than those with more severe disease $(89 \%)$. Thirty-one patients had subcutaneous nodules, i.e., $18 \%$ of those with definite rheumatoid arthritis, and in every case the L.S.T. was positive.

When activity of disease was graded on clinical grounds only, those with inactive rheumatoid arthritis yielded $54 \%$ positive results compared with $88 \%$ in those with active disease. The administration of steroids did not alter the incidence of positive tests. No correlation was found between the L.S.T. and activity of disease as measured either by erythrocyte sedimentation rate or haemoglobin levels.

One hundred patients had radiographic bone changes typical of rheumatoid arthritis. Of the 30 men in this group all but one had positive tests, and the corresponding figure for the 70 women was $70 \%$. The overall figure was $85 \%$ positive in the presence of typical radiographs. 


\section{Discussion}

A large number of tests are now available for the demonstration of rheumatoid factor in the blood of patients with rheumatoid arthritis. Most of these use an indicator which may be biologically active or inactive as classified in Table II.

The majority of these techniques are tedious and time consuming. Recently a slide test (the L.S.T.), which is both easy to perform and gives rapid results, has been developed commercially. In over 600 cases we have demonstrated that it is a reliable test in rheumatic disorders. The parallel study of the D.A.T. showed only four occasions on which the tests were not in agreement.

\section{TABLE II}

I. Indicator Biologically Active

\section{Sheep Cells}

(a) Agglutination. The differential sheep cell agglutination test, described by Rose et al. (1948) (D.A.T. or S.C.A.T.)

This classical test may be modified in several ways:

(1) Heterophil antibodies absorbed (Heller et al., 1949)

(2) Sheep serum used as the diluent (Heller et al., 1952)

(3) Sheep cells treated with tannic acid and coated with human globulin (Heller et al., 1954)

(4) Rheumatoid factor isolated as euglobulin by dialysis (Ziff et al. 1956).

(b) Inhibition Test (Ziff et al., 1956) 2. Human Erythrocytes Sensitized human

II. Indicator Biologically Inactive

1. Latex Particles

(a) Agglutination. Standard latex fixation test (Singer and Plotz, 1956)

This may be modified as follows :

(1) "Drop" and tube methods, L.F.T. (Rheins $e$ al., 1957; Thomas et al., 1957)

(2) Latex slide test (L.S.T.)

(3) Using euglobulin

(b) Inhibition Test (Hall et al., 1958)

2. Bentonite
Flocculation test (B.F.T.) (Bozicevich et al., 1958) Slide test

III. No Indicator Used

F11 precipitation test (Epstein et al., 1956)

There is evidence that sera containing greatly elevated gamma globulins, e.g., syphilis and disorders of the liver, may produce more false positive results with the L.S.T. than with the D.A.T., but these conditions rarely give rise to confusion in the differential diagnosis of rheumatic disorders. For routine laboratory use, therefore, the L.S.T. would appear to be the most practicable of the tests at present available in this field. For research purposes the quantitative aspects of the D.A.T. may be advantageous, although it should be noted that the L.S.T. provides a roughly quantitative measure, and correlates well with the titre of the D.A.T.
Patients with rheumatoid arthritis were classified without knowledge of the serological results to ensure an unbiased study. Of 246 patients with definite or probable rheumatoid arthritis, $85 \%$ gave a positive result. On the criteria laid down by the American Rheumatism Association 43 more were classified as definite than by our clinical criteria. The weakness of the American Rheumatism Association classification is the equal weight given to each item. For instance, nodules score no more than a single swollen joint, although by many they are regarded as pathognomonic of rheumatoid arthritis, and in our series all cases with nodules had a positive L.S.T.

Extent of disease may have some bearing on the L.S.T. since those with mild arthritis had fewer positive results. To test the hypothesis that burnt-out rheumatoid arthritis gives a negative test, the L.S.T. was related to the activity of the arthritis. Inactive disease judged clinically was found to show fewer positive results. On the other hand, activity judged by the E.S.R. and haemoglobin did not correlate with the L.S.T. and gave no support to the hypothesis. The presence of radiological changes of rheumatoid arthritis increased the likelihood of the test being positive, but $15 \%$ of patients with such changes had a negative result. In keeping with the results of other workers using the D.A.T. (Ball, 1952), the incidence of false positive tests was low $(3.8 \%)$.

We are indebted to Professor S. J. Hartfall for his encouragement in this study, and to Mr. S. Wisdom, chief technician, for technical assistance and willing co-operation.

\section{REFERENCES}

Ball, J. (1952). Ann. rheum. Dis., 11, 97.

Bozicevich, J., Bunim, J. J., Freund, J., and Ward, S. B. (1958). Proc. Soc. exp. Biol. (N.Y.), 97, 180.

Epstein, W., Johnson, A., and Ragan, C. (1956). Ibid., 91, 235.

Greenbury, C. L. (1957). Association of Clinical Pathologists Broadsheet No. 18.

Hall, A. P., Mednis, A. D., and Bayles, T. B. (1958). New Engl. J. Med., 258, 731 .

Heller, G.. Jacobson, A. S., and Kolodny, M. H. (1949). Proc. Soc. exp. Biol. (N.Y.), 72, 316.

exp. Biol. (N.Y.), Kammerer, W. H. (1954). J. Immunol., 72, 66. - - and Schuman, R. L. (1952). Ibid., 69, 27.

Rheins, M. S., McCoy, F. W., Burrell, R. G., and Buehler, E. V. (1957). J. Lab. clin. Med., 50, 113 .

Ropes, M. W., Bennett, G. A., Cobb, S., Jacox, R., and Jessar, R. A. (1959). Arthr. and Rheum., 2, 16.

Rose, H. M., Ragan, C., Pearce, E., and Lipman, M. O. (1948). Proc. Soc. exp. Biol.' (N.Y.), 68, 1 .

Singer, J. M., and Plotz, C. M. (1956). Amer. J. Med., $21,888$.

Thomas, J. W., Robinson, H. S., Gofton, J. P., Stuckey, M., and Lamont-Haverts, R. (1957). Canad. med. Ass. J., 76, 621.

Waller, M. V., and Vaughan, J. H. (1956). Proc. Soc. exp. Biol. $(N . Y), 92,198$.

Wright, V.' (1959). Amer. J. Med., 27, 454.

Ziff, M., Brown, P., Lospalluto, J., Badin, J., and McEwen, C. (1956). Ibid., 20, 500. 